\title{
Psychological evaluation by means of an on-line computer
}

\author{
A. P. BYERS \\ Associates for Psychotherapy and Education, Inc., Pueblo, Colorado 81003
}

\begin{abstract}
The use of an on-line microcomputer-based testing system in a private clinical psychology practice is described. Advantages and disadvantages are discussed. Information about procedures and fees are presented.
\end{abstract}

The private practice and general psychological services described herein are located in Pueblo, Colorado. The population area is 100,000 or more persons. It is a private corporation known as the Associates for Psychotherapy and Education, Inc. This corporation offers a wide range of psychological services, with a multidisciplinary staff. Two clinical psychologists, a social worker, and a nurse therapist (trained in family therapy) make up the staff. One secretary/receptionist manages the office.

The services offered are individual and group psychotherapy, marital and family psychotherapy, sexual dysfunction therapy, treatment for alcohol and drug abuse, psychological evaluations (including neuropsychological evaluations), and child custody evaluations. Additional activities and services are management consultation, workshops, and feminist therapy (with a special emphasis on therapy for women alcoholics).

The clientele served by these clinicians are, for the most part, self-referred or referred by former clients. In addition, referrals are also received from local physicians, attorneys, the courts, and social agencies.

Very few of the clients in therapy are on medication or are being seen in connection with an inpatient or hospital program. Consultation and coordination with medical persons is most usually experienced at our initiation.

Psychological testing is carried out in several contexts and in response to a variety of referral needs. Some therapists in this clinic request, at the time of intake, that clients undergo a battery of tests to assist in a more rapid assessment of needs, to determine psychological status, and to assist in establishing outcome goals.

In the case of the custody evaluations, there is a combination of clinical interviews, home visits, and psychological testing of the parties involved. Sometimes the children are interviewed and tested in addition to the adults, if their age and the situation indicates a need for that.

Additionally, the courts may request evaluations for a second opinion regarding involuntary commitment of a person to a state institution.

Neuropsychological assessments are requested in cases of persons who are suspected of having brain damage or have known brain injury. Such referrals come through local psychiatrists, neurologists, attorneys, and the courts, as well as rehabilitation programs.

Local psychiatrists frequently refer a client for testing to assist them in a more accurate differential diag. nosis to facilitate better planning and treatment.

Normally, all of the above testing services are carried out by either the clinical psychologist or a psychometrician, under the direction of the psychologist when individual testing techniques are required (such as intelligence testing and personality assessment with projective techniques). Testing with paper-and-pencil instruments, as well as the projective and individually administered instruments, is scored by hand. In the past, pencil-and-paper tests were scored by a computer scoring service to which the answer sheet was mailed. A week or 2 later, the results were returned to the office. The typical psychological report and write-up (following the above testing techniques) would take anywhere from 1 to 2 months, depending on the other demands on the clinician's time. This delay was the case, even though the testing procedure itself may have taken only a few hours or, at most, a day.

The advent of an on-line microcomputer dramatically changed the testing services in this office. Johnson and Williams (1978) described the basic pioneering work in developing assessment techniques on an on-line microcomputer at the Veterans Administration Hospital in Salt Lake City, Utah. Johnson, Giannetti, and Williams (1978) described a study to clinically validate an on-line microcomputer-based Minnesota Multiphasic Personality Inventory (MMPI) interpretation program. Johnson, Williams, Klingler, and Giannetti (1977) discussed some strategies for developing clinically acceptable reports from such systems. Some of the problems that psychiatric patients might encounter when they interact with computer terminals were investigated by Cole, Johnson, and Williams (1976). Klingler, Miller, Johnson, and Williams (1977) evaluated the use of a computer system for the assessment of mental health patients during an intake process. A comparison of computerized and traditional noncomputerized testing was carried out by Klingler, Johnson, and Williams (1976). These studies provide a more detailed background for this 
brief statement of the clinical use of the on-line microcomputer in a private practice.

The Associates for Psychotherapy and Education, Inc., purchased an 11/02 processor, an LA120 printer, two VT-100 terminals, and test administration software through Psych Systems in Baltimore, Maryland.

\section{AVAILABLE TEST SERVICES}

\section{The Dissimulation Index (QI)}

This test is primarily used to determine at the outset whether or not the computerized testing services are appropriate for a person. The test takes about $5 \mathrm{~min}$ to administer and is immediately scored to determine whether or not to proceed with testing.

\section{The Beck Depression and Hopelessness Scales (Beck)}

This test gives a quick evaluation of the degree of severity of a person's feelings of depression and hopelessness. Also, it suggests the extent to which the person is a suicidal risk. The Beck test takes about 5 min to administer and score.

\section{The Intellectual Screening Battery (ISB)}

This test is made up of the Shipley-Hartford verbal and abstraction scores, with items added to assess recent and remote memory. In addition, the Wechsler Adult Intelligence Scale (WAIS) arithmetic subtest is used for assessing arithmetical reasoning. The ISB is highly correlated with the WAIS (in the 90-110 IQ range, $\mathrm{r}=.8$ ), and it functions as an excellent screening device for general intelligence. The ISB takes about $45 \mathrm{~min}$ to administer and score.

\section{The Minnesota Multiphasic Personality Inventory (MMPI)}

The MMPI, with over 100 scales scored and interpreted, is the most widely used objective personality assessment instrument. Statements about the subject's normal and/or psychopathological features are given. Diagnostic and prognostic interpretations are offered, as well as treatment suggestions and risks. Among other things, information regarding chronic low back pain, tendency toward litigation, and misuse of medication can be obtained. This instrument takes about $45.60 \mathrm{~min}$ to administer and score. It is a most powerful diagnostic and treatment tool.

\section{The Strong-Campbell Interest Inventory (SC-II)}

The Strong-Campbell contains 400 items that result in a comparison of a subject's interests with the interests of men and women in various occupational groups. The scores are reported in terms of general occupational themes, special scales, administrative indexes, basic interest scales, and specific occupational scales. This test is useful with persons 16 years of age and older for current decision making and for those 14-18 years of age for future and tentative planning. This test takes about $30 \mathrm{~min}$ to complete.

\section{The Social History (SHX)}

This instrument is particularly helpful in new-patient assessment. It provides information about an individual's family, childhood and adolescent adjustment, vocational and marital adjustment, quality of life, recent stressful events, and use of chemicals. This instrument takes about $20 \mathrm{~min}$ to complete. However, the time is highly variable, due to the nature of the branching logic, which excludes or includes questions based on client responses. The number of questions can vary from 90 to 200 .

\section{Index of Somatic Problems (ISP)}

The ISP contains, in a true-false format, 15 to 20 physical complaints (depending on the subject's responses) most commonly found in a psychiatric population. Based on factorial methods, it is intended as a quick screening tool. It is not considered a comprehensive medical history. This instrument takes $5-20 \mathrm{~min}$ to administer, score, and interpret.

\section{The Symptom Check List-90-R (SCL-90-R)}

The SCL-90-R functions to isolate psychopathology in nonpatient, medical, and psychiatric groups. It is an excellent screening device to avoid medical treatment for psychopathological problems and to assist in sorting out psychopathological aspects of medical problems. This test is administered and scored in about $15 \mathrm{~min}$.

\section{The Visual Searching Task (VST)}

The VST provides an excellent screening device for neurological impairment. It has been shown to be very sensitive in discriminating between psychotic and neurological impairment.

\section{DISCUSSION}

Our experience with this system has been that we can reduce the cost to the client for the collection of test data as well as increase the speed of data availability. We have essentially instant turnaround, with the scoring and interpretation immediately available through the narrative printout. Psychologists are now more likely to recommend psychological testing due to cost and work-load reduction. Thus, more psychological testing can be carried out, to the betterment of the client. Clients report a more positive attitude about this testing procedure, as compared with our previous paper-andpencil method. The immediate feedback is extremely rewarding to the clients, providing positive reinforcement for having invested their time in the data collection. Less secretarial time is required. Our secretary now invests only about $5 \mathrm{~min}$ to start a client on the testing battery with the terminal.

Our experience with psychological assessment admin- 
Table 1

Psychological Evaluation Price Schedule

Cost

\section{Individual Prices}

1. Dissimulation Index $(\mathrm{QI}) \ldots \ldots \ldots \ldots \ldots$. . . . . . . . . . . . . . . . . .

2. Beck (BECK) . . . . . . . . . . . . . . . . . . . . 20.00

3. Intellectual Screening Battery (ISB) . . . . . . 25.00

4. Minnesota Multiphasic Personality Inventory

(MMPI) . . . . . . . . . . . . . 50.00

5. Strong-Campbell Interest Inventory (SC-II) . . . . . 40.00

6. Social History (SHX) . . . . . . . . . . . . 25.00

7. Index of Somatic Problems (ISP). . . . . . . . . 15.00

8. Symptom Check List (SCL-90-R) . . . . . . . . 30.00

9. Visual Searching Task (VST) . . . . . . . . . 25.00

10. Battery $1 \ldots \ldots \ldots \ldots \ldots \ldots$

11. Battery $2 \ldots \ldots \ldots \ldots$. . . . . . . . . 135.00

12. Projective Techniques (i.e., Rorschach, House-Tree-

Person, etc.; additional paper-and-pencil testing also available)

13. Wechsler Adult Intelligence Scale (WAIS) . . . . . . 75.00

14. Wechsler Intelligence Scale for Children-Revised (WISC-R) . . . . . . . . . . . . 75.00

15. Neuropsychological Assessment (cost is varied)

Batteries of Tests (Reduced Rate)

Battery 1 (QI, ISB, MMPI, SC-II, SHX)

115.00

Battery 2 (QI, BECK, ISB, MMPI, SHX,

ISP, SCL-90-R) . . . . . . . . . . . . . 135.00

Note-Items 1-11 are available with the on-line computer. All others are individually administered. Battery 1 is primarily designed to collect information to assist in vocational and career planning and decision making. Battery 2 is primarily designed to collect information to assist in medical and nonmedical services to better understand the subject's overall mental health and social adjustment.

istered, scored, and interpreted through an on-line computer system has, thus far, led to an awareness of additional strengths and weaknesses of such a modality of testing. The strength of the system is that it takes a client less time to complete testing on the computer terminal than it does by paper and pencil. We also eliminate errors due to the client's becoming "out of synch" between the answer sheet and the test booklet. This type of error could render an entire test invalid and waste the client's time. The on-line computer testing procedure does "force the client" to answer all items. The clients, for the most part, like the technology and electronic "wizardry" of the computer terminal. In short, the clients rather enjoy the process, as compared with tolerating the paper-and-pencil process. Staff time required for scoring and interpretation has been eliminated, since the computer scores. interprets, and produces a narrative printout of these instruments.
At this point, my experience also points to some specific weaknesses of this system. Much of the instrumentation is useful only for screening. For example, the SHX is a bit brief and cannot substitute for an adequate social history. The ISB is an excellent indicator of intellectual adaptabilities only for the midrange of IQ scores from 90-110. The scores outside this range, both at the upper and lower ends of the distribution, are not as useful, because the error of estimate in these outer ranges is too severe. Thus, it is difficult to use the computer narrative just as it is produced from the printer for release to a referring person and/or agency. It is necessary to reinterpret the computer printout in terms of the request for the evaluation. This, of course, is a common problem with psychological evaluations, in that they have meaning mostly in terms of the questions raised by the referring person or the clients themselves. Additionally, there are some computer interpretation printouts that may, in some ways, disagree with a clinician's judgment. At that point, the clinician will have to make a choice between his own private interpretations based on his clinical experience and training and the interpretations of the computer.

A suggested price list for testing services using the computer is included in Table 1 so that the reader might have the opportunity to assess the economics of on-line computerized testing.

\section{REFERENCES}

Cole, E. B., Johnson, J. H., \& Williams, T. A. When psychiatric patients interact with computer terminals: Problems and solutions. Behavior Research Methods \& Instrumentation, $1976,8,92-94$.

Johnson, J. H., Giannetti, R. A., \& Williams, T. A. A selfcontained microcomputer system for psychological testing. Behavior Research Methods \& Instrumentation, 1978, 10, 579-581.

Johnson, J. H., \& Williams, T. A. Clinical testing and assessment using a microcomputer for on-line psychiatric assessment. Behavior Research Methods \& Instrumentation, 1978, 10, 576-578.

Johnson, J. H., Williams, T. A., Klinglen, D. E., \& GiANnETTI, R. A. Interventional relevance and retrofit programming: Concepts for the improvement of clinician acceptance of computer-generated assessment reports. Behavior Research Methods \& Instrumentation, 1977, 9, 123-132.

Klingler, D. E., Johnson, J. H., \& Williams, T. A. Strategies in the evaluation of an on-line computer-assisted unit for intake assessment of mental health patients. Behavior Research Methods \& Instrumentation, 1976, 8, 95-100.

Klingler, D. E., Miller, D. A., Johnson, J. H., \& Williams, T. A. Process evaluation of an on-line computer-assisted unit for intake assessment of mental health patients. Behavior Research Methods \& Instrumentation, 1977, 9, 110-116. 